\title{
1 A FAMÍLIA E AS PESSOAS COM EXPERIÊNCIA DE DOENÇA MENTAL
}

| José Carlos Carvalho ${ }^{1} \mid$

É incontornável falar-se da família.

Porque se convencionou, pela importância que ela tem, pela importância que ela teve, pela importância que lhe é devida.

No Plano Nacional de Saúde Mental 2007-2016 (Ministério da Saúde, 2008), numa análise à situação em Portugal, não pode deixar de fazer uma referência especial à reduzida participação de utentes e familiares na definição das políticas de saúde mental. Neste sentido, sendo a família a entidade que devia preencher as necessidades emocionais e psicológicas de todos os seus membros, muitos profissionais de saúde e investigadores têm dedicado o seu estudo às questões da família: da sobrecarga da doença na família, nos cuidadores... a todo o seu impacto e o que ela representa para a sociedade.

Definir família, é mais complexo que falar ou pensar nela. Gameiro (1992) definia como uma rede complexa de relações e emoções (...) e a simples descrição de uma família não serve para transmitir a riqueza e a complexidade relacional desta estrutura, enquanto Figueiredo (2012), caracterizava-a pelas inter-relações estabelecidas entre os seus membros (...) numa rede múltipla de relações de intercontextualidade.

Em todas as definições são encontrados elementos comuns:

- Uma instituição com valores e características próprias;

- Um grupo de pessoas ligadas por laços de parentesco;

- Sistema de relações interdependentes, com funções de manutenção, proteção e sobrevivência (Carvalho, 2012).

A família, é a principal unidade básica de desenvolvimento pessoal e onde se vivenciam um conjunto de experiências fundamentais para a formação da personalidade, mas as transformações na sociedade, também implicaram mudanças na organização e estrutura familiar, com novas formas de agregados e de famílias, com um aumento da diversidade e das interações conjugais.
Esta visão da família e esta preocupação advém também da investigação realizada com uma das entidades patológicas mais emblemáticas na Psiquiatria (esquizofrenia) e do conhecimento das famílias, das suas preocupações e das suas necessidades, pelo que entendemos família como as pessoas que coabitam e que mantém um relacionamento frequente com a pessoa com experiência de doença mental.

São tratadas as pessoas que sofrem da doença, os familiares, os cuidadores, os progenitores... mas quase sempre numa visão muito parcelar e muito redutora, não de uma forma integrativa, numa visão da família como um todo.

A importância da família é inquestionável na ajuda ao seu processo de tratamento, cura ou de reabilitação, pelo que deve ser um elo de ligação, um verdadeiro parceiro de cuidados e que a Enfermagem e em particular na área da Saúde Mental, deve aproveitar e potenciar.

Ao falar-se da pessoa com experiência de doença mental, é inevitável falar da família. Como referia José Ortega y Gasset, "O homem é o homem e a sua circunstância”. Este desafio será um dos maiores para a Enfermagem de Saúde Mental: atender as pessoas com experiência de doença mental e as suas famílias, mas como um todo.

Mas, a família é sempre um recurso?

Ao longo dos tempos, a família era considerada como a culpada de muitos dos males que as doentes padeciam. Culpabilizar a mãe por toda a(s) dificuldade(s) do desenvolvimento psicológico foram um clássico ao longo dos anos. Mas ainda hoje, algumas teorias são invocadas para justificar essas opções. A hipótese da mãe esquizofrenizante, a teoria do duplo vínculo (DoubleBind), a ideia de "cisma conjugal" entre outras (Yacubian \& Neto, 2001).

Vários investigadores (anos 60-70) debruçaram-se sobre a forma como a "atmosfera familiar" pode influenciar o curso da doença, nomeadamente na esquizofrenia. Muitas outras teorias responsabilizavam a família, sem, no entanto, haver grande consistência empírica (Yacubian \& Neto, 2001).

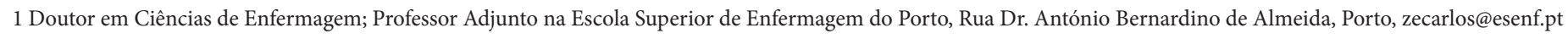


Esta preocupação crescente com a família contribuiu também para uma mudança positiva de atitude, com a diminuição do estigma a que estiveram sujeitos durante muitos anos e o consequentemente distanciamento dos profissionais de saúde mental, que no passado, foram influenciados pelas "teorias culpabilizantes" das famílias. Com o envolvimento da família assistiu-se a um progressivo aumento do número de pessoas com perturbações psicóticas de evolução crónica que se mantém integrados na família, a utilizar os serviços apenas nas situações de descompensação aguda (Carvalho, 2012).

Mas esta aproximação e envolvimento fez aparecer um amplo espetro de dimensões da vida familiar, que as famílias se viram confrontadas, com problemas que não tinham, com dificuldades que encontraram no seu desempenho, também como cuidadoras. Por outro lado, na perspetiva dos doentes e das pessoas com experiência de doença mental, um maior contacto dos seus familiares com os serviços de saúde mental e a uma maior participação da família no seu tratamento foi favorável A família constitui uma dimensão importante da satisfação dos doentes com os serviços de Saúde Mental. Considerando-se que a satisfação dos doentes pode contribuir para uma melhor adesão ao regime terapêutico e favorecer um impacto positivo dos serviços de saúde mental, o envolvimento dos familiares torna-se ainda mais pertinente.

As principais referências nesta área reforçam a sua importância. Hanson (2005) considera-o um foco relevante para a prática da Enfermagem, uma vez que engloba áreas como: papéis, comunicação, poder, tomada de decisão e as estratégias de coping, e Wright e Leahey (2009) reforçam a ideia de que é indicada uma intervenção, a nível da família, sempre que um membro da família apresenta um problema e que possa ter impacto nos outros membros. Para tal, avaliar a dinâmica familiar, as relações familiares, a família como um todo e não apenas a soma das partes, deverá ser uma das dimensões a apostar pelos profissionais de saúde e em particular pelos enfermeiros de Saúde Mental, uma vez que é claramente assumida a importância da família no tratamento e na reabilitação do doente.

Para estes desafios, porque também o são, será necessária uma atividade diagnóstica para compreender e avaliar a dinâmica/relações familiares, com diversos recursos, desde o genograma e o ecomapa, o uso dos modelos de Hanson, de Friedman, de Calgary e Dinâmico de Avaliação e Intervenção Familiar (MDAIF) e onde o processo de cuidados possa centrado na família, assumindo os referenciais dos Modelos em uso.
O recurso a instrumentos de avaliação como o FACES IV (Family Adaptability and Cohesion Evaluation Scales), poderá permitir uma intervenção mais direcionada e consequentemente mais eficaz. As famílias com características mais rígidas apresentam maior dificuldade em superar as dificuldades porque não permitem a ajuda externa. Este instrumento, baseado no modelo circumplexo de Olson ou modelo do sistema conjugal e familiar, permite fazer o estudo das famílias quanto à coesão e da flexibilidade/adaptabilidade e categorizá-las, originando dezasseis tipos familiares, que são agrupados em quatro grandes tipos: equilibrado, moderadamente equilibrado, meio-termo e extremo, ficando com a noção do tipo de família, mais: coesa, flexível, rígida, caótica... (Carvalho et al., 2014)

Relativamente aos diagnósticos de Enfermagem, o foco de eleição na família é o processo familiar, as interações positivas ou negativas e os padrões de relacionamento entre os membros da família (Carvalho, 2012).

$\mathrm{Na}$ Classificação das Intervenções de Enfermagem (NIC), na manutenção do processo familiar (p. 392), são defendidas atividades tais como:

- "Determinar os processos familiares típicos;

- Determinar a rutura nos processos familiares típicos; - Identificar os efeitos de mudança nos papéis sobre o processo familiar." (...)

Assim como na Classificação dos Resultados de Enfermagem (NOC), no funcionamento familiar ( $p$. 393) são referidas as capacidades da família para atender as necessidades dos seus membros através das transições desenvolvimentais, avaliando a demonstração dos seguintes indicadores:

- "Socializa com os novos membros da família;

- Regula o comportamento dos membros;

- Membros familiares desempenham os papéis esperados;

- Adapta-se às crises inesperadas." (...)

Estes são alguns dos exemplos que a Enfermagem pode fazer, para ajudar estas famílias a ultrapassar as dificuldades nos processos familiares.

Se a família é realmente importante, devemos reconhecê-la sempre e não apenas em determinados momentos e dar resposta ao que é defendido também no Plano Nacional de Saúde Mental 2007-2016, aumentar a participação das famílias nos processos de tratamento, reabilitação e cura das pessoas com experiência de doença mental. 


\section{REFERÊNCIAS BIBLIOGRÁFICAS}

Bulechek, G., Butcher, H., \& Dochterman, J. (2010). Classificação das Intervenções de Enfermagem (NIC) (4a ed.). Rio Janeiro: Mosby Elsevier.

Carvalho, J. C. (2012). Diagnósticos e intervenções de enfermagem centradas no processo familiar, da pessoa com esquizofrenia. Revista Portuguesa de Enfermagem de Saúde Mental (8), 52-57.

Carvalho, J. C., Freitas, P., Leuschner, A., \& Olson, D. (2014) Healthy functioning in families with a schizophrenic parent. Journal of Family Psychotherapy, 25(1), 1-11. doi: 10.1080/08975353.2014.881685

Figueiredo, M. H. (2012). Modelo dinâmico de avaliação e intervenção familiar - Uma Abordagem Colaborativa em Enfermagem de Família. Loures: Lusociência.
Hanson, S. (2005). Enfermagem de cuidados de saúde à família: Teoria, prática e investigação. Loures: Lusodidacta.

Moorhead, S., Johnson, M., Maas, M., \& Swanson, E. (2010). Classificação dos Resultados de Enfermagem (NOC) (4 ed.). Rio Janeiro: Mosby Elsevier.

Ministério da Saúde. Alto Comissariado da Saúde. Coordenação Nacional para a Saúde Mental (2008). Plano Nacional de Saúde Mental 2007-2016 - Resumo Executivo. Lisboa: Coordenação Nacional para a Saúde Mental.

Wright, L., \& Leahey, M. (2010). Enfermeiras e famílias: Um guia para avaliação e intervenção na família (5 ed.). Lisboa: Editora Roca.

Yacubian, J. \& Neto, F. (2001). Psicoeducação fami-liar. Família, Saúde \& Desenvolvimento, 3(2), 98-108.

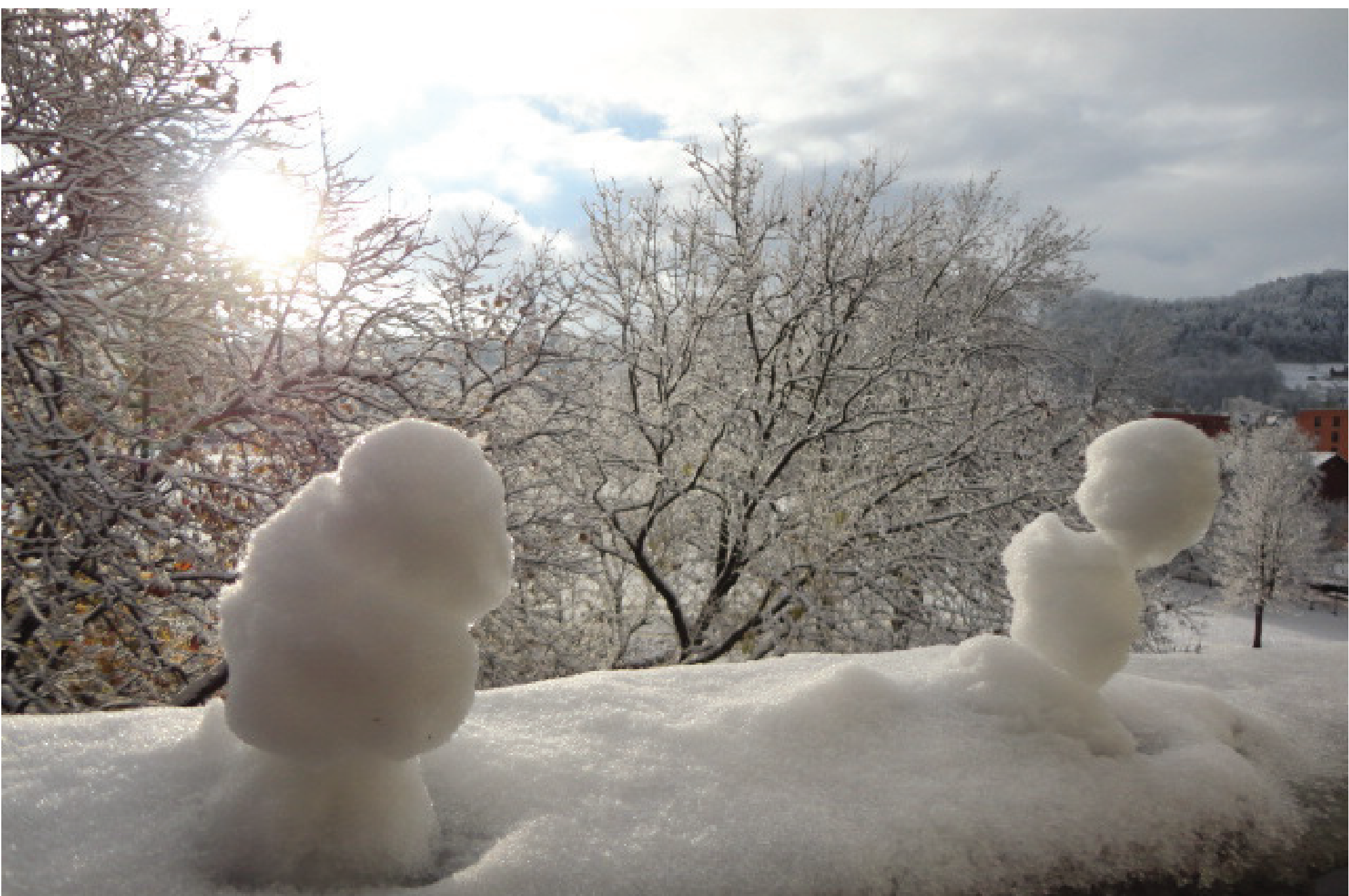

